\title{
Early Outcomes in Anterior Cruciate Ligament Reconstruction: Full Tibial tunnel technique compared to all-inside technique
}

\author{
OCTAV MARIUS RUSSU ${ }^{1}$, EMILIAN CIORCILA ${ }^{1}$, ANDREI MARIAN FEIER ${ }^{1 *}$, RADU FLEACA ${ }^{2}$, SANDOR GYORGY ZUH ${ }^{1}$, \\ ANDREI CONSTANTIN IOANOVICI ${ }^{3}$, ISTVAN GERGELY ${ }^{1}$ \\ 'Medicine and Pharmacy University of Tirgu Mures, Department of Orthopedics and Traumatology, 38 Gheorghe Marinescu Str., \\ 540136, Tirgu Mures, Romania \\ 'Lucian Blaga University of Sibiu, Department of Orthopedics and Traumatology, 10 Victoriei Blvd., 550024, Sibiu, Romania \\ ${ }^{3}$ Clinical County Emergency Hospital of Tirgu Mures, Department of Gastroenterology, 50 Dr. Gheorghe Marinescu Str., 540136, \\ Tirgu Mures
}

\begin{abstract}
The all-inside technique for ACL reconstruction uses the semitendinous muscle tendon as a graft, and postoperative pain is slightly reduced. Through the full tibial tunnel technique, better anatomical graft placement is obtained with promising results, yet there are only few scientific articles comparing the two techniques. The main objective is evaluation of results after $A C L$ reconstruction by comparing the clinical results of the two surgical techniques. A prospective study was conducted that included 63 eligible patients according to pre-established criteria. The technique used was randomly indicated to each patient. Demographics and clinical examination results were collected and subsequently stored. The assessment tools used were the International Knee Documentation Committee (IKDC), Knee injury and Osteoarthritis Outcome Score (KOOS) and the Visual Analogue Scale (VAS) with a 6-month follow-up period. The statistical analysis was performed for preoperative follow-up scores, at 3 and 6 months. All patients were operated by the same surgical team under spinal anesthesia with nerve block and tourniquet applied.In regards to IKDC and KOOS scores, the difference between the two interventions was not statistically significant ( $p=.579$ and $p=.710$ ). Postoperative pain was slightly reduced in patients in the all-insidel group but without any statistical significance compared to full-tibial tunnel technique $(p=.259)$. There were no graft ruptures or late postoperative complications. Regarding IKDC, KOOS and VAS evaluating tools, there is no statistically significant difference between the two evaluated methods for ACL reconstruction, all-inside and full tibial tunnel at 3 months and 6 months after surgery.
\end{abstract}

Keywords: all-inside technique, full tibial tunnel technique, anterior cruciate ligament, sports orthopedics

Anterior cruciate ligament $(A C L)$ reconstruction is being performed more than 100.000 times in a year only in the United States[1]. The full tibial tunnel technique is considered a standard technique by many surgeons, whereas in the all-inside technique, the the tibial tunnel is replaced by a tibial socket [2-5]. Older studies concluded that all-inside technique had a faster rehabilitation time and pain after surgery is slightly diminished [4].

Graft positioning is also reported to be superior in the allinside technique with promising biomechanical results [ 4 , 6-8]. However, only few studies reported the clinical outcomes after the all-inside technique $[9,10]$. Therefore, our main objective was to compare the outcomes of $A C L$ reconstruction using the two techniques: full tibial tunnel and all-inside technique at 3 and 6 months after the surgery, by starting from the working hypothesis that stipulates that between the IKDC, KOOS and VAS scores at 3 and 6 months postoperative regarding the two surgical procedures will be a difference that is statistically different.

\section{Experimental part}

Materials and methods

A prospective, randomized clinical study was conducted in the Orthopaedics and Traumatology Clinic of Tîrgu Mure' Clinical County Hospital. After obtaining consent from Institutional Review Board, patients with clinical and magnetic resonance imaging (MRI) confirmed $A C L$ ruptures were screened for inclusion.

Inclusion criteria were: male and female physical active patients with $A C L$ injury aged 16-45, body mass index under
25 , physical therapy for 3 weeks prior to surgery. Exclusion criteria were: multi-ligament lesions, grade 2 or higher chondral lesions, trauma in the same knee in the past 12 months, gestation or other hormonal disorders. The patients were randomly assigned for one of the two techniques using a random number generator in which each individual had a specific assigned number, based on his first presentation in our clinic. Patients were not blinded for the surgical technique. Ipsilateral semitendinosus and gracilis muscle tendons were used for the new ACL autograft for each patient in the full tibial tunnel group and semitendinosus muscle tendon alone for the all-inside group. All patients were operated by the same surgical team under spinal anesthesia with nerve block and tourniquet, while supportive treatment was given for the postoperative pain.

\section{Outcome evaluation}

Demographic related data was collected by a study nurse at the time of enrollment. Knee laxity was assessed using the clinical Lachman testand RolimeterTM, Aircast $\circledast$ device in $25^{\circ}$ of flexion. Outcome evaluation forms included the International Knee Documentation Committee (IKDC) Subjective Knee Evaluation Form and Knee Injury and Osteoarthritis Outcome Score (KOOS) preoperatively, at 3 and 6 months postoperative. To evaluate the pain we used the VAS (visual analog scale) pain score at 3 and 6 months after the surgery.

All the included patients had complete $A C L$ ruptures confirmed arthroscopically at the time of surgery. Out of

*Phone: 0040747501392 
104 patients selected, 63 patients were included after meeting the criteria; 31 were assigned for the full tibial tunnel method and 32 for the all-inside technique. Full follow-up ( 6 months) was achieved for all 63 patients.

\section{Statistical analysis}

Statistical analysis of outcomes was performed for preoperative, 3 months and 6 months follow-up scores. The null-hypothesis $\left(\mathrm{H}_{0}\right)$ is that there is no significant statistical difference between the two techniques regarding IKDC, KOOS scores and VAS pain score. MannWhitney test was used to analyze demographic data. Subjective scores (IKDC, KOOS and VAS) were analyzed using 2-way repeated-measures ANOVA for the mentioned follow-ups. Alpha value was set at .05 (Cl 95\%). GraphPad InStat (GraphPad, San Diego, USA), Epilnfo v. 7.1.4.0 (Centers for Disease Control and Prevention, Atlanta, USA) and Microsoft $\circledast$ Excel v15.0 (Redmond, Washington, USA) were used to analyse data.

\section{Results and discussions}

No graft ruptures or complications were recorded. The demographic data showed no significant difference between the two groups (Mann-Whitney $\mathrm{U}$ test and 2Proportion test). As for the IKDC Subjective Knee Score (table 1) and KOOS (table 2), the difference on outcomes between the two interventions (all inside versus tibial approach) was not statistically significant ( $p=.579$ and $p=.710)$.

The VAS pain score showed slightly better improvement postoperatively using the all-inside technique compared to the tibial approach, but the result was not statistically significant ( $p=.259$; table 3 ).

The most important finding of our study was that there is no difference between the two techniques regarding subjective outcomes reported at different follow-up times. At 6 months follow-up there were no differences between the two techniques in regards to IKDC, KOOS and VAS evaluating tools. Our findings are similar to those recently published in the literature even though there are only few studies reporting comparative outcomes between techniques. Anatomically reconstruction of the $A C L$ is considered a gold standard in the world of orthopedics as it provides a facile graft placement, better outcomes and lower pain after surgery. The most common graft used in all-inside technique is the quadrupled semitendinosus tendon, therefore preserving hamstring strength and allowing a faster rehabilitation and return to daily activities $[3,12,13]$.

In a recent study, fixation with bioresorbable screws increased the incidence of perioperative cysts [14] and numerous materials have been described as perspectives and future projections for these cases [15]. Fixations were made with two adjustable cortical-loops in the all-inside group and one adjustable cortical-loop and one bioresorbable interference screw for the full tibial tunnel, thus providing superior mechanical resistance and avoidance of the aforementioned complications. In a prospective study on 150 patients Lubowitz et al. found no differences between all-inside and full tibial tunnel $A C L$ reconstruction techniques [12]. The team also evaluated other scores, narcotic consumption, tibial and femoral widening but with differences between the groups only regarding VAS pain score. Compared with baseline, VAS score was lower in the all-inside group.

The IKDC Subjective Knee Evaluation form is officially validated as knee-specific patient-reported health status and used in numerous studies regarding $\mathrm{ACL}$ reconstruction outcomes. The sample number of patients might be too low but compared to the literature, the current study

Table 1

INTERNATIONAL KNEE DOCUMENTATION COMMITTEE SCORE OUTCOMES AT DIFFERENT FOLLOW-UPS

\begin{tabular}{|l|l|l|l|l|}
\hline & All inside & Tibial & Statistics & Test \\
\hline Preoperative & $60.02 \pm 16.61(\mathrm{n}=31)$ & $58.32 \pm 12.85(\mathrm{n}=32)$ & & \\
\cline { 1 - 3 } & & & \multirow{2}{*}{$\mathrm{P}=.579$} & 2 way repeated ANOVA \\
\cline { 1 - 3 } & $71.18 \pm 11.68(\mathrm{n}=31)$ & $70.05 \pm 11.62(\mathrm{n}=32)$ & & \\
\hline
\end{tabular}

Table 2

KNEE INJURY AND OSTEOARTHRITIS OUTCOME SCORE OUTCOMES AT DIFFERENT FOLLOW-UPS

\begin{tabular}{|c|c|c|c|c|}
\hline & All inside & Tibial & Statistics & Test \\
\hline Preoperative & $52.48 \pm 10.24(n=31)$ & $53.81 \pm 12.60(n=32)$ & \multirow{3}{*}{$\mathrm{P}=.710$} & \multirow{3}{*}{2 way repeated ANOVA } \\
\hline 3 months & $74.41 \pm 13.15(n=31)$ & $75.37 \pm 11.35(\mathrm{n}=32)$ & & \\
\hline 6 months & $83.45 \pm 9.58(\mathrm{n}=31)$ & $82.68 \pm 8.68(n=32)$ & & \\
\hline
\end{tabular}

Table 3

VISUAL ANALOGUE SCALE OUTCOMES AT DIFFERENT FOLLOW-UPS

\begin{tabular}{|l|l|l|l|l|}
\hline & All inside & Tibial & Statistics & Test \\
\hline Preoperative & $2.4 \pm 0.9$ & $2.3 \pm 0.7$ & & \\
\cline { 1 - 2 } one day postop & $2.8 \pm 1.1$ & $3.1 \pm 1.2$ & \\
\cline { 1 - 2 } & & & \\
two weeks postop & $.2 \pm 2.1$ & $.9 \pm 1.8$ & & \\
\hline 3 months postop & $-1.5 \pm 1.9$ & $-1.3 \pm 2.9$ & & \\
\hline
\end{tabular}


provides similar level of evidence. Patients with associated intra-articular lesions were also included and may affect the desired or expected results.

Literature reports are not clear whether any of the techniques is superior to the other. The only demonstrated advantage of the all-inside technique is the less pain measured at early follow-ups, but the end-pointresults are similar.

\section{Conclusions}

In regard to IKDC, KOOS and VAS evaluating tools, there is no statistically significant difference between the two evaluated methods for $A C L$ reconstruction, all-inside and full tibial tunnel at 3 months and 6 months after surgery, hence failing to reject the null hypothesis.

\section{References}

1.J ANSSEN, K.W., ORCHARD, J.W., DRISCOLL, T.R., VAN MECHELEN, W., Scand J Med Sci Sport, 22, 2012, p. 495-501.

2.BURNHAM, J.M.,2, MALEMPATI, C.S., CARPIAUX, A., IRELAND, M.L, JOHNSON D.L. Arthrosc Tech, 6, no. 2, 2017, p. e275-e282.

3.WILSON, A.J., YASEN, S.K., NANCOO, T., STANNARD, R., SMITH, J.O., LOGAN, J.S., Arthrosc Tech, 2, no. 2, 2013, p. e99-e104. 4.LUBOWITZ, J.H., Arthroscopy, 22, no. 8, 2006, p. el-11.
5.BLACKMAN, A.J ., STUART, M.J., J Knee Surg, 27, no. 5, 2014, p. 347352

6.SMITH, P.A., SCHWARTZBERG, R.S., LUBOWITZ, J.H., Arthroscopy, 24, no. 10, 2008, p. 1184-1189.

7.KUROSAKA, M., YOSHIYA, S., ANDRISH, J.T., Am J Sports Med, 15, no. 3, 1987, p. 225-229.

8.WALSH, M.P., WIJDICKS, C.A., ARMITAGE, B.M., WESTERHAUS, B.D., PARKER, J.B., LAPRADE R.F., Am J Sports Med, 37, no. 8, 2009, p. 1539-1547.

9.YASEN, S.K., BORTON, Z.M., EYRE-BROOK, A.I., PALMER, H.C., COTTERILL, S.T., RISEBURY, M.J., WILSON, A.J., Knee, 24, no. 1, 2017, p. 55-62

10.SCHURZ, M., TIEFENBOECK, T.M., WINNISCH, M., SYRE, S., PLACHEL, F., STEINER, G., HAJDU, S., HOFBAUER, M., Arthroscopy, 32, no. 2, 2016, p. 332-337.

11.LUBOWITZ, J.H.1, SCHWARTZBERG, R., SMITH, P., Arthroscopy, 29, no. 7, 2013, p. 1195-1200.

12.YOSMAOGLU, H.B., BALTACl, G., OZER, H., ATAY A., Knee Surg Sports Traumatol Arthrosc, 19, no. 8, p. 1287-1292.

13.MARTINEK, V., FRIEDERICH, F.N., Arthroscopy, 15, no. 3, p. 317320.

14. TRAMBITAS, C., POP, T.S., TRAMBITAS, A.D.M., DOROBANTU, D.C., BRINZANIUC K., Rev Chim (Bucharest), 68, no. 2, 2017, p. 387-389

$\overline{\text { Manuscript received: } 20.08 .2018}$ 